\title{
La tauromaquia y los otros festejos taurinos. Un complejo festivo fragmentado
}

Tauromaquia and other bullfighting festivals. A fragmented festive complex

\author{
Héctor Medina Miranda \\ Centro de Investigaciones y Estudios Superiores en Antropología Social- \\ Occidente
}

Guadalajara, Jalisco, México

\section{RESUMEN}

Las fiestas de toros conforman un amplio y diverso complejo iberoamericano. Sin embargo, durante siglos se ha distinguido a la tauromaquia como la más civilizada de estas celebraciones, considerándola un arte que sólo los entendidos pueden apreciar. A partir de las reflexiones del filósofo Francis Wolff, se emprende un recorrido histórico y antropológico para mostrar cuán diversas son las tradiciones taurinas en España y México, así como las tensiones que hay entre ellas.

PALABRAS CLAVE: tauromaquia, fiestas de taurinas, toros, ideología nacional, identidad

\section{ABSTRACT}

The taurine fests are a wide and diverse Ibero-American complex. However, for centuries the tauromaquia has been distinguished as the most civilized of these celebrations, considering it an art that only connoisseurs can appreciate. Based on the reflections of the philosopher Francis Wolff, a historical and 
anthropological journey is undertaken to show how diverse the bullfighting traditions are in Spain and Mexico, as well as the tensions that exist between them.

KEY WORDS: tauromaquia, bullfights, bulls, national ideology, identity

\section{INTRODUCCIÓN}

Definir el toreo ha sido una empresa que ha ocupado a muchos especialistas. En la mayor parte de estos empeños, la tauromaquia parece distanciarse del resto de los festejos taurinos, al encumbrarse por su antigüedad, su estética, su estadio evolutivo y su difusión. Entre los trabajos más destacados que se han publicado recientemente acerca de las corridas de toros se encuentran los del filósofo francés Francis Wolff. Su principal obra acerca del tema es Filosofía de las corridas de toros (2010 [2007]), en la cual propone un interesante ejercicio de definición de estas y busca aportar argumentos a favor de su defensa. El texto comienza con un diálogo socrático, en el que él mismo se identifica con el maestro griego, quien provoca a sus discípulos con el método de la mayéutica. Sócrates los invita a reflexionar qué son las corridas de toros y estos se debaten en definirlas como un juego, un deporte, un arte, un espectáculo o un rito. Al final, el filósofo socrático parece decantarse y resolver que las corridas son simultáneamente un combate y un arte, la "muerte pública y leal de los toros salvajes, ${ }^{1}$ precedida por una lidia regulada" (ibídem: 22). Afirma que se trata de una lucha cuyo resultado es seguro, pero cuya ejecución siempre es incierta, ya que el torero debe adaptarse para dominar al bovino. Su carácter plástico radica en la inteligencia para imponer ese dominio, que hace de la embestida la materia prima de la obra de arte. En esos breves instantes el torero impone su marca y da forma a su creación con curvaturas, series y remates, entre otros.

Cuando considera definir la tauromaquia como un acto sacrificial de las fiestas de toros, parece más dubitativo. En alguna parte dice que "la ética de las corridas de toros es el combate, poder contra poder, no la del sacrificio, del débil por el fuerte. Es que, aunque el combate en el ruedo sea fundamentalmente desigual, es básicamente leal. El toro no es tratado como un animal dañino, ni como un chivo

\footnotetext{
${ }^{1}$ Cabe mencionar que, si bien en esta parte dice "salvajes", en otro lado menciona que el toro de lidia no es ni un animal domesticado, ni salvaje: "es un animal bravo" (Wolff 2010 [2007]: 60), criado para ser los más opuesto al hombre y combatir contra él, lo suyo es un "salvajismo domesticado".
} 
expiatorio que se deba sacrificar." (ibídem: 46). Con ello busca echar un capote para esquivar las astas de las asociaciones protectoras de animales; pero, cuando argumenta acerca del perfil heroico del torero y del carácter ritual del combate, las cosas cambian y asevera: "Los valores en los que se basa la tauromaquia son los del combate, pero la corrida echa sus raíces múltiples tanto en el sacrificio ritualizado de un animal maravilloso como en el duelo formalizado entre dos luchadores bravos y nobles" (ibídem: 111). Wolff no pretende hacer un análisis antropológico de las características del ritual, tampoco intenta realizar un estudio histórico de sus antecedentes para demostrar el supuesto origen sacrificial. Más bien, pareciera interesado en mostrar que no es fácil definir a la tauromaquia con claridad -sobre todo cuando se es un apasionado-, como tampoco lo es renunciar a las caracterizaciones que hicieron sus discípulos ficticios. Quizás sólo se siente seguro cuando define a los toros como "un ritual que conduce necesariamente al suplicio o como un combate que lleva inevitablemente a la muerte" (ibídem: 113). Sin embargo, la finalidad última dice en otro lado- no es vencer al animal, sino que es un arte que depende de la inspiración del artista y no tiene otro fin que la belleza.

Precisamente, es la muerte que persigue una finalidad artística lo que ha creado una distancia, que parece infranqueable, entre la tauromaquia y otros festejos taurinos. El mismo Wolff se identifica con uno de sus interlocutores imaginarios cuando dice: "llamad juego o deporte a las tauromaquias populares, que tienen su grandeza, pero no a nuestra fiesta. Preguntaos por qué todos esos juegos taurinos [...] no han superado generalmente las fronteras de la tribu ni lo límites de su región, por qué no han alcanzado nunca el brillo universal de las corridas de toros" (ibídem: 31). Denominar "tribus" a las sociedades que practican los festejos populares taurinos es, sin lugar a dudas, una terrible expresión de soberbia o chulería -como se diría en el ámbito taurino-, que discrimina para jactarse de la superioridad de la corrida artística. Las otras sólo serán resabios del salvajismo, propio de los primeros estadios evolutivos de la humanidad.

Así, la tauromaquia se opone a otras tradiciones fuertemente arraigadas en el suroeste europeo. Aún más, dada la "universalidad" que se le atribuye, se presenta como superior y madre de todas aquellas que se han desarrollado en el continente americano. De manera contradictoria, la tauromaquia será la versión más evolucionada y refinada de su especie, a la vez que es la más antigua, rasgo que -conjeturan sus panegiristas- se confirma con la persistencia de la muerte del animal, que es una supervivencia de antiguos sacrificios en las sociedades totémicas. Sólo esta forma civilizada y ancestral será definida en España como "el espectáculo más nacional”. Allende el Atlántico, en el continente americano, 
otros festejos taurinos seguirán caminos análogos, fragmentando un complejo festivo compuesto por tradiciones hermanadas y en el que, de vez en cuando, algunas buscan imponerse sobre las otras. El propósito de este artículo es hacer un bosquejo de las principales tensiones que existen entre los toreos de diferentes latitudes y sus consecuencias, empleando algunos casos de España y México. El punto de partida es la descripción de la manera en que los panegiristas han buscado el origen de la tauromaquia, cómo la han definido y posicionado con relación a otros festejos taurinos. Luego, nos desplazaremos al otro continente.

\section{RITO, JUEGO Y ESPECTÁCULO}

Hay consenso acerca de que la tauromaquia habría adquirido una forma característica entre finales del siglo XVIII y la primera mitad del XIX. En ese periodo comienza a emplearse la denominación de "tauromaquia" para este nuevo tipo de celebraciones. Tenemos entonces la publicación del matador José Delgado, "Pepe Hillo", 2 titulada La Tauromaquia o Arte de torear (1796); pero la estandarización no parece ser definitiva hasta la aparición del libro Tauromaquia completa o el arte de torear en plaza tanto a pie como a caballo (1836), de Francisco Montes "Paquiro". Algunos consideran que el origen de este tipo de corridas está en la contribución realizada por Francisco Romero (1700-163), a quien se le atribuye la invención de la muleta para la suerte de espada (véase por ejemplo Fernández Moratín, (1850 [1777]). Otros, dicen que el empleo de la muleta es anterior, ya que, en un manuscrito -con letra del siglo XVIII- ${ }^{3}$ se habla de una suerte que podría resultar similar. El manuscrito se titula Cartilla en que se notan algunas reglas de torear a pie en verso y prosa, el nombre del autor es desconocido. ${ }^{4}$ Se trata de un texto que en el que una de las reglas enumeradas se refiere a la suerte de matar, burlando al animal con el "lienzo blanco", que se

\footnotetext{
${ }^{2}$ Muchas veces aparece también como Pepe Illo, pero empleo esta ortografía ya que es la más común.

${ }^{3} \mathrm{El}$ documento no tiene fecha, pero así lo dató, por el tipo de escritura, Luis Carmena y Millan en su Tauromaquia. Apuntes bibliográficos y el catálogo de la Biblioteca Nacional Española coincide al respecto.

${ }^{4}$ El manuscrito también se conoce como Cartilla de la Biblioteca de la casa ducal de Osuna, donde se albergó antes de ser depositado en la Biblioteca Nacional de España con la asignatura MSS/11257. También puede consultarse una versión en la Biblioteca Digital Hispánica:

http://bdh-rd.bne.es/viewer.vm?id=0000191605\&page=1.
} 
supone es un antecedente de la muleta. Conviene reproducir un fragmento para dar cuenta de la difusión que tenía dicho lance.

\author{
Es la suerte más extraña \\ la que en el país no se usa, \\ pues mi afición no la escusa, \\ para quien tuviese maña, \\ pues a ninguno le daña \\ (quien la pueda ejecutar) \\ que es con un lienzo el llamar \\ al toro, y con esta acción \\ se logra más perfección \\ en el modo de torear. ${ }^{5}$
}

El lienzo blanco también, dice el mismo texto, podría emplearse en una suerte que se denominaba la "estocada de ley". Así lo confirma otro documento de la época, que también daba instrucciones a los que deseaban torear a pie, en alguna parte dice: "Hay una suerte muy vistosa, aunque muy poco usada, que llamamos de la ley, que es cuando se hace con un lienzo blanco en vez de capa: sirve esta tanto para burlar al toro, como para matarle" (García Baragaña 1750: 11). En ambos fragmentos, queda claro que en aquel tiempo la corrida consistía, principalmente, en toreo a caballo y lances de capote; que no existía un tercio dedicado al toreo con muleta; que dicho acto sólo se presenciaba de manera muy eventual. Tampoco se llamaba tauromaquia y, quizás, aún no había adquirido pretensiones artísticas; pero ya era un espectáculo, característica que vincula al toreo de a pie con las corridas caballerescas, que antiguamente practicaron los nobles. Veamos algunas disertaciones que abordan la relación entre el toreo a pie y el de a caballo, en las que además se discute la antigüedad de la suerte de matar.

\footnotetext{
${ }^{5}$ Cartilla en que se notan algunas reglas de torear a pie..., regla XVI, fojas 18 frente y vuelta. Una transcripción de este manuscrito puede encontrarse también en Cossío (1965: 71-79).
} 
Ángel Álvarez de Miranda (1998 [1962]) busca demostrar que las corridas populares eran más antiguas que las corridas espectaculares. Para ello, echa mano de una de las descripciones más antiguas de dichos eventos en la Península Ibérica, la cual podemos encontrar en las famosas Cantigas de Santa María de Alfonso X. ${ }^{6}$ Estas dan cuenta de celebraciones nupciales en la que corrían con un toro por las calles. El novio y sus amigos conducían al animal atado con una cuerda al tiempo que lo burlaban con sus chaquetas y lo enfurecían lanzándole dardos. Cabe subrayar que en estos festejos la muerte del toro no era un elemento originario, sino que, al concluir el festejo, el animal era devuelto al campo o a su lugar de procedencia. Eventualmente, podría ser llevado a un matadero, pero eso no formaba parte de la celebración. Estas corridas parecieran estar relacionadas con otras contemporáneas que son conocidas como toros de la pea, enmaromados, toros de cuerda o capeas. Aunque, en la actualidad, estas no se llevan a cabo en contextos nupciales, recuerdan en su forma a aquellos antiguos festejos.

Álvarez asegura que de estas celebraciones populares derivan las corridas caballerescas, que se realizaron en bodas y en muchos otros momentos, las cuales pudieron haber aparecido hacia los siglos XII y XIII. Estos festejos de la nobleza hicieron de la muerte un elemento fundamental, lo que obligó a que se multiplicara el número de reses que empleaban, convirtiéndose así en un vistoso espectáculo. Era una innovación que transformó la corrida en peligrosa lucha, lo cual tiene varias implicaciones. Por un lado, nos muestra que la antigua práctica popular era un ritual en el que el animal atado no era un adversario, sino un instrumento de juego útil para lograr sus fines rituales; mientras que en las corridas de la nobleza el bovino se convierte en un adversario del hombre. Por otro lado, explica que, cuando el rito se convirtió en un combate, surgió "la necesidad de la victoria como epílogo". De ahí, lo que él considera la gran paradoja del toreo español, la cual consiste en que "sólo cuando dejó de ser cuestión sacral comenzó a parecer sacrificio" (ibídem: 81). En otras palabras, la corrida popular era originalmente un acto ritual y sagrado o, al menos, con implicaciones religiosas, pero no tenía propósitos sacrificiales; el toreo caballeresco era principalmente un evento lúdico secularizado, pero culminaba con la muerte del bovino.

Más tarde, algunos rituales populares adoptarían la muerte del toro, bajo la influencia del toreo caballeresco. Así, este elemento, que no era originalmente sacrificial, se realizó -eventualmente- con propósitos "mágicos", de manera que

${ }^{6}$ Texto del siglo XIII. 
se "convirtió en tema ritual un tema profano" (ibídem: 92). Más tarde, los ritos populares perderían su carácter sagrado y se convertirían en juegos. La muerte del toro se practicaría también en otro toreo que sería una prolongación del espectáculo caballeresco, al que identifica como la "corrida moderna" y corresponde formalmente a lo que se identifica como tauromaquia. Se trata de tres tipos de toreo que terminarían por converger en el ámbito lúdico. Empero, el toreo caballeresco entraría en decadencia desde del siglo XVII y desaparecería en el XVIII. A partir de entonces, el moderno torero a pie sería el protagonista de esos espectáculos que ambos compartían.

Álvarez de Miranda considera que estos nuevos lidiadores de la tauromaquia se inspiraron, no en las formas que tenía la muerte en el toreo caballeresco, sino en las adaptaciones que habían hecho las corridas populares. Para demostrar esto último recurre a la Cartilla en que se notan algunas reglas de torear a pie y al texto de García Baragaña, documentos de los cuales he reproducido un par de fragmentos líneas atrás. ${ }^{7}$ Por un lado, haciendo uso de lo que estos textos dicen acerca de la "estocada de ley", deduce que se trata de una costumbre de origen rural, ya que queda claro que era muy rara en el toreo caballeresco, y que sólo poco a poco se introdujo en las corridas urbanas. Por otro lado, asegura que existen indicios de que en los festejos populares se emplearon sábanas de cama para torear, de ahí que los toreros modernos optaran por emplear un lienzo blanco, que más tarde cambiaría de color y se llamaría muletilla.

De esta guisa, concluye que en la tauromaquia persisten algunos elementos del antiguo trato ritual del toro, a pesar de que sea de un espectáculo moderno, buscando enfatizar que estamos ante el tránsito de un rito religioso hacia el juego. Precisamente, asegura, "el germen lúdico que todo rito posee por naturaleza favorece este tránsito" (ibídem: 152). Quiere decir que con el juego se suprime la referencia a las deidades y se pierde la conciencia del carácter religioso del antiguo ritual y termina encuadrándose en la esfera profana, aunque el proceso nunca se completa del todo. ¿Qué implicaciones tiene esto? Al parecer, todas estas celebraciones siempre fueron juego y conservarán elementos de su pasado ritual, pero algunas han optado en convertirse en espectáculos. El trabajo de Álvarez de Miranda es, sin lugar a dudas, un análisis interesante y pionero, a pesar de su ambigüedad y la obstinada insistencia en la continuidad, con las que subestima el papel de las rupturas y la innovación, como si todo permaneciera por siempre y todo tuviera su origen en un pasado remoto.

${ }^{7}$ Cossío (1965: 51) había publicado el documento previamente y Álvarez de Miranda recurrió a dicha versión. 
Este modelo ha sido de enorme relevancia para las investigaciones posteriores. Algunas mostraron que el espectáculo de masas se ha conformado en la convivencia del toreo de a pie y el de a caballo en el siglo XVI, aunque ya en el siglo XV hay indicios de espectáculos taurinos con protagonistas a pie. Al respecto conviene revisar el trabajo de Araceli Guillaume-Alonso (1994, 2010 y 2016), el cual muestra documentación que confirma el protagonismo del torero popular de a pie en algunos espectáculos de la época; a su vez, señala el año de 1671 como el momento decisivo en el que aparece un torero a pie profesional con un salario, empleando los libros de cuentas de las corridas. Considera que ya entonces se trataba de un auténtico negocio. Sin embargo, acepta que "el giro decisivo que ha introducido el espectáculo tauromáquico en su modernidad [...] es la división del tiempo concedido a cada torero para cumplir su trabajo [...] en tres tercios de duración teóricamente parecida" (Guillaume-Alonso, 2010: 83, 100). Esta división tripartita de la corrida parece que fue definitiva en el momento en que Francisco Montes "Paquiro" publicó su Tauromaquia (1836), aunque un siglo antes ya estaba en gesta.

Asimismo, Guillaume-Alonso (1994) considera que, desde el siglo XVI, el aspecto lúdico prevalecía en la mayoría de las fiestas y juegos taurinos. Busca demostrar que, con mucha frecuencia, las celebraciones populares se fundamentaron en una inversión carnavalesca del mundo y el objetivo no solía ser la muerte del toro. Principalmente, se trata de burlar al astado en un universo temporal que se torna de cabeza. ¿Se refiere a una inversión ritual?, no se abunda en el asunto. La información proporcionada nos obliga a pensar que la incorporación de la muerte del toro en las corridas populares no fue tan relevante como lo creyó Álvarez de Miranda, que quizás los casos que él cita para argumentar la incorporación de dicha suerte son excepcionales. Cabe agregar que la descripción de los festejos extremeños del toro nupcial, que emplea Álvarez para plantear su hipótesis, es mucho más reciente. Fue realizada por Publio Hurtado en los pueblos de la montaña a finales del siglo XIX. ${ }^{8}$ Queda claro que es más factible que la suerte de matar a pie se haya generado en el contexto de los espectáculos que organizaban los nobles.

${ }^{8}$ El texto de Hurtado dice: "En Extremadura, en la región de Hervás, Casas del Monte, La Zarza y otras, existe la costumbre de comenzar las ceremonias nupciales dos días antes de la boda. En este día, el novio y sus amigos sacan un toro del matadero, atado por los cuernos con una fuerte maroma. Recorren con él todo el pueblo, toreándolo con las chaquetas, hasta llegar a la ventana de la prometida, donde es muerto, después de que el novio le ha colocado, un par de banderillas previamente adornadas por la novia" (1989 [1902]: 267). 
Bartolomé Benassar estaría en total desacuerdo con estas últimas líneas. En uno de sus trabajos más relevantes dice: "no es posible aceptar la interpretación de Álvarez de Miranda según la cual la suerte de matar sería la herencia más importante recibida por la tauromaquia moderna del toreo caballeresco" (2000: 41). Al respecto debo subrayar que la lectura de este destacado historiador hispanista es errónea. Como ya he mencionado antes, para Álvarez de Miranda la muerte del toro habría pasado de la corrida caballeresca a los festejos populares $\mathrm{y}$, de estos, a la tauromaquia. Sin embargo, aquella premisa con la que Bennassar polemiza sí parece ser la tesis de José María Cossío (1965: 47), a quien también trae a colación, si bien hay algunos aspectos que es justo matizar.

En una parte de su magnífica obra enciclopédica, Cossío dice: "Aunque el toreo a pie no adquiere personalidad e importancia sustantiva hasta el siglo XVIII, en el apogeo del toreo caballeresco era indispensable [...] para ayuda y socorro de los caballeros, sin mencionar las ocasiones del toreo plebeyo en fiestas corrientes o capeas pueblerinas" (1965: 48). Él desea destacar que el empeño a pie constituía parte de toreo a caballo. De ahí, considera que El tratado de la brida y jineta y de las caballerías que en entrambas sillas se hacen y enseñan a los caballos y de las formas de torear a pie y a caballo -escrito por Diego Ramírez de Haro en 1551es el primero de la bibliografía de las tauromaquias. Debo insistir en que las instrucciones están dedicadas a los caballeros que durante la lidia se ven obligados a apearse. Cossío cita otros documentos del mismo tipo, de años posteriores, lo que efectivamente sugiere que el origen de la tauromaquia está en las corridas caballerescas, pero no descarta la existencia de un toreo popular.

Bennassar también arremete contra Guillaume-Alonso, quien, como ya he dicho, presenta documentación en la que es evidente que la muerte del toro no es un elemento esencial o recurrente en los festejos populares. De alguna manera, pareciera que Guillaume-Alonso abonaba a la hipótesis de Cossío y que sus datos confirmaban que la suerte de matar se había originado en los festejos de la nobleza. Bennasar se pronuncia en oposición con una frase que es un leitmotiv para los defensores del origen sacrificial de la tauromaquia, para quienes la suerte de matar no podría ser un legado del toreo caballeresco, ya que admitirlo "supondría reconocer que la tauromaquia popular no practicaba esta suerte" (Bennassar 2000: 41). Con el objeto de demostrar la importancia de la muerte del toro en el ámbito popular, recurre a investigaciones destacadas acerca del matadero sevillano, de su papel en la elaboración de las técnicas, los recursos y 
las suertes, que dieron origen a la tauromaquia moderna. ${ }^{9}$ Estos trabajos aseguran que los toreros de a pie más antiguos, de los que se había encontrado documentación, procedían, en su mayoría, del matadero de la capital andaluza. Que en ese recinto se corrían toros a pie como un espectáculo autónomo, que los espectadores observaban desde los tejados. Al respecto, la documentación más temprana proviene del siglo XVI y se trata de quejas y prohibiciones para que estas no se llevaran a cabo, ya fuera porque la gente-que trepaba por los muros y se encaramaba en los tejados- dañaba el edificio o porque la carne era de peor calidad y se descomponía más rápidamente cuando las reses eran lidiadas, por mencionar algunas.

Lo importante para Bennassar, como para los mismos autores que él sigue, es demostrar la importancia del "laboratorio sevillano" en el surgimiento de la tauromaquia, pero es inevitable preguntarse por qué insiste en que la suerte de matar proviene del ámbito popular. Al parecer, se trata de un acto de congruencia y solidaridad con sus colegas, quienes desde la década de 1980 han argumentado a favor del origen totémico y sacrificial de las fiestas de toros..$^{10}$ No obstante, entre el siglo XVI (época a la que se remontan las primeras pruebas de los festejos populares con muerte de toro) y el tiempo de las presuntas sociedades totémicas de la península ibérica hay muchos siglos de por medio. Además, la documentación disponible deja claro que se trataba de una suerte que sólo en pocas ocasiones se practicaba en celebraciones populares. Más aún, contamos con la muy destacada contribución del etnólogo francés Frédéric Saumade (2006), quien ha puesto los puntos en las íes desde el presente etnográfico de los distintos tipos de corridas europeas. La conclusión es que dicha suerte no es un elemento estructural, que es sólo una de las variantes de un amplio complejo festivo que se extiende allende las fronteras españolas. Más adelante volveremos a este tema. ${ }^{11}$

De momento, cabe notar que no es posible clasificar o diferenciar a las corridas de toros entre actos rituales y eventos lúdicos. Si en la época de Alfonso X fueron prácticas religiosas, es evidente que tuvieron un alto contenido lúdico. Para el

\footnotetext{
${ }^{9}$ Dos de ellos son, por un lado, el libro colectivo de García-Baquero, Romero de Solís y Vázquez Parladé (1980); por otro, un artículo de García-Baquero (1990). El tercer documento es de Luis Toro Buiza, pero Bennassar no indica el título, al parecer, puede tratarse de Sevilla en la historia del toreo y la Exposición de 1945, reeditado por Pedro Romero de Solís en 2002.

${ }^{10}$ Los interesados pueden consultar Medina (2014).

${ }^{11}$ Véase también Désveaux y Saumade (1998).
} 
siglo XVI queda claro que son prácticas lúdicas que han adquirido formalidad ritual. No quiero decir que sean rituales dedicados al culto a las divinidades o exclusivamente religiosos, sino que son eventos compartidos y regulados, que se repiten y crean sentido para los actores y participantes. Son producto de las fuerzas sociales que contribuyen a la reproducción de un tiempo y un espacio colectivo, para lo cual rompen temporalmente con las convenciones. En los mataderos, al parecer, las regulaciones no eran lo más común, los reglamentos se crearon en una clara incorporación al mundo del espectáculo. Este, dice Bennassar (2000), pudo haber surgido cuando Madrid se convirtió en sede de la Corte (1561) y se hizo clara distinción entre las corridas reales y las que organizaba la ciudad. En aquel tiempo, fueron escritos reglamentos para que el toreo caballeresco se acoplara a los manuales de cortesía de los caballeros. Entonces surge lo que este autor llama "una sociedad del espectáculo". Pero recordemos que paradójicamente, para él, la muerte del toro no deriva de los espectáculos caballerescos, sino que es de origen popular. A veces no es posible disentir con nuestros colegas más cercanos.

\section{EL ARTE, UN ESPECTÁCULO DE ELITE}

Como bien ha observado Frédéric Saumade (1996), la etimología griega de la palabra "tauromaquia" muestra que es resultado de una construcción culta, distante del ámbito popular. ${ }^{12} \mathrm{Al}$ parecer, el tratado firmado por José Delgado ("Pepe Hillo") le asignó este nombre, obra que pudo haber sido escrita por algún erudito amante de las fiestas taurinas. Se presume que el matador era analfabeto. La Tauromaquia o Arte de torear fue publicada por primera vez en 1796. El Diccionario de Autoridades, de la primera mitad del siglo XVIII, no daba cuenta de este término, en su lugar tenía la palabra "toros", la que definía de la siguiente manera: "En plural se toma por la fiesta en que los corren, y sortean" (Real Academia Española, 1739). Esta categoría parecía más inclusiva, contemplaba todos los eventos en los que se practicaba el toreo, "el ejercicio, o arte de torear" (ibídem). "Torear" era definido como "lidiar los toros en la plaza, hiriéndolos, y haciendo suertes". En otra acepción se puede leer: "Significa también hacer burla de alguno con acciones, o entreteniéndole" (ibídem). La burla parece ser un elemento común en todos estos términos y, aun cuando se habla de heridas, no se contempla la muerte del astado. En cuanto a los participantes, el toreador era

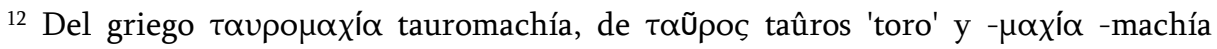
'lucha'. Real Academia Española: Diccionario de la lengua española, 23.a ed., [versión 23.4 en línea]. <https://dle.rae.es> [consultado el 25 de noviembre de 2020]. 
"el que lidia toros a caballo, a distinción del torero"; por su parte, el torero sería "el que por oficio, o precio torea de a pie en las plazas" (ibídem).

La palabra "tauromaquia" no figuró en los diccionarios hasta la segunda década del XIX, como "el arte de lidiar y matar a los toros" (Real Academia Española, 1817). Sólo entonces, la muerte del bovino apareció como un elemento característico. A finales del mismo siglo, la definición omitiría el asunto de la muerte y se definiría casi como un sinónimo del "toreo": "arte de lidiar los toros" (Real Academia Española, 1884). Para entonces, la tauromaquia se había convertido en la práctica más representativa de los festejos taurinos. Esa frase persiste en las últimas versiones de los diccionarios. Algo similar sucedería entre "toreador" y "torero", ambos se emplean ahora para referirse a la persona que torea, sin importar la técnica. En lo que respecta a su definición como "arte", en un principio parece que se emplea para referirse a una habilidad, a una maña, a una destreza o a un oficio; pero, al concluir el siglo, se evidencia una intensión de equipararlo con las bellas artes.

Así, en algunos manuales de la primera mitad del siglo XVII, la palabra "arte" figura como una habilidad o destreza, por ejemplo, en Arte da cavallaria da gineta e estardiota, bom primor de ferrar et albeiteria, de Antonio Galvam D’Andrade (1678), o en Arte de enfrenar de Francisco Pérez de Navarrete (1626). Más tarde, tenemos las cartillas, la publicación de Pepe Hillo y la de Francisco Montes "Paquiro", las cuales se refieren al arte del toreo como una profesión. Pero, antes de que concluyera el siglo XIX, ya se mostraban interesantes esfuerzos por caracterizarlo como un arte mayor. En buena medida, parece que se trata de una manera de defenderse ante sus detractores, que calificaban de bárbaras a las corridas de toros. Los ejercicios bárbaros serían, a partir de entonces, los festejos populares, que representaban estadios previos a la existencia de la tauromaquia, restos de un pasado que renunciaban a evolucionar (véase, por ejemplo, Fernández de Moratín 1850 [1777]; Millán 1890; San Juan de Piedras Albas 1927).

$\mathrm{Al}$ definirse de esta manera, la tauromaquia se distanció de los festejos populares, a la vez que se declaró heredera del espectáculo de la nobleza y se autoproclamó como un arte civilizado y civilizador. En su tratado, Pepe Hillo reivindicó el pasado de las fiestas de toros señalando que los héroes de la nación fueron toreros. Menciona entre ellos al Cid Campeador, al emperador Carlos V, a Felipe IV y al conquistador de Perú Francisco Pizarro, entre otros. El propósito es homologarse con aquella nobleza torera, hacerse uno con "los brazos más ilustres de la Nación [que] han sostenido y sostienen la grata afición al Toreo" (Delgado, 
1946 [1796]: 9). Muy similar fue el texto introductorio de Francisco Montes "Paquiro", quien destaca que los primeros en lidiar toros fueron los nobles: "Si la nobleza y relevantes prendas de las personas que dedican a tal o cual diversión, honesta se entiende, es motivo para reputar por buena y tenerla en estima, la lucha de toros gozará la preeminencia, por haber sido el más valiente caballero español el primero a quien se vio lidiarlos" (1983 [1836]: 19).

Estos dos tratadistas precursores de la tauromaquia, insistieron en que esta se convertiría en un festejo nacional, lo cual se consiguió a finales del XIX. Así lo constatan las publicaciones del romanticismo y el costumbrismo español. Por ejemplo, el libro clásico titulado Los españoles pintados por sí mismos dedicó el primer capítulo al torero de origen andaluz, definiéndolo como un tipo "esencialmente nacional", que consiguió sustituir en el toreo "la ignorancia y la barbarie" por "la inteligencia y el verdadero valor". Se presume que la tauromaquia nacida en Andalucía es superior a cualquier otro tipo de festejo taurino, como muestra veamos el siguiente fragmento:

\begin{abstract}
El Torero siempre es andaluz: es cualidad indispensable cuya sola posesión asegura al neófito un puesto delante de la fiera, y ser reputado desde luego como apto y conveniente para el oficio. Con ser andaluz se adelanta la mitad de camino; porque la santa costumbre ha vinculado este ejercicio entre los garbosos hijos del Betis, y por eso los valencianos, manchegos, murcianos o extremeños que se dedican al toreo, lo primero que hacen es olvidarse del país en que nacieron: adoptar, además del uniforme de plaza, el traje de calle más común en los andaluces: imponerse una jerga técnica de los compaes. mezclarse en los calientes bromazos que corren de continuo, y a la vuelta de un año de trasteo, ya hay hombre: aunque haya salido de la ribera del Miño, la metamorfosis es completa: ya pertenece a la buena raza [...] (Rodríguez Rubí, 1843: 3).
\end{abstract}

Antes del fin de siglo, el conde de las Navas le denominaría El espectáculo más nacional (1899) en el que se ofrece una defensa del origen autóctono de las fiestas de toros, frente a otros que buscaban su génesis en el extranjero. Asimismo, el autor expresa que los toreros de oficio habían elevado su profesión a "verdadero arte". Con otros panegiristas, coincidía en que el "progreso" se había conseguido suprimiendo ciertas suertes "bárbaras" y con "la creciente inteligencia del público de los tendidos en el tecnicismo del arte, traducido en disminución de brutales exigencias" (Navas, 1899: 54-55). En ese momento ya se piensa en "arte" como un rasgo con implicaciones estéticas -creador de belleza-, 
apegado a preceptos "cultos y civilizados". Más tarde, se hablaría de "toreo moderno".

Este proceso que acabo de analizar coincide con lo que Frédéric Saumade (1996) ha calificado como "imperialismo de la tauromaquia", a través del cual la variedad de distintas celebraciones regionales, que consistían en la lidia a pie, fue reducida y racionalizada para la elaboración de un espectáculo moderno coherente. El mismo autor explica que, hacia el siglo XVIII, los programas que se elaboraban en el norte de España incluían toreros aragoneses, navarros y riojanos bajo la denominación genérica de "toreros navarros". De esta manera se pretendía distinguirlos de los matadores andaluces. Por supuesto, la tradición septentrional no pudo contra la arrolladora corriente meridional con su marcada vocación nacionalista. Saumade considera que los llamados navarros no tuvieron tanto éxito ya que su estilo no tenía "un aspecto tan moderno" y resultaban tosco en comparación a la "ágil soltura de una estética liviana" de los andaluces (ibídem: 135). El toreo norteño fue calificado como arcaico, brutal, portador de la torpeza atribuida a la corrida popular y a lo irracional. Por su parte, otras prácticas tradicionales -como las corridas portuguesas, landesas y camarguesasoptaron por reafirmar su propia identidad taurómaca. En este contexto, surgen, en las últimas décadas del siglo XIX, los famosos encierros de Pamplona, celebración popular que parece oponerse a los preceptos establecidos por el espectáculo nacional.

Más recientemente, fuimos testigos -a través de los medios- de un peculiar debate en torno a los festejos taurinos en Cataluña, donde la célebre silueta del toro, insignia del brandy Veterano del Grupo Osborne, se ha convertido en un tabú, ya que ha llegado a ser considerado un emblema del nacionalismo español. De ahí que, en 1998, un grupo independentista catalán derribara la última valla que había en esta comunidad con la imagen del negro bovino. Dos décadas después, el debate se centraría en la prohibición de la fiesta nacional. La discusión fue puesta sobre la mesa por la Plataforma PROU!, ${ }^{13}$ apoyada por los partidos independentistas catalanes, como una Iniciativa Legislativa Popular. La solicitud de prohibición se fundamentaba en argumentos animalistas, los cuales apelaban al maltrato, el dolor y el sufrimiento de los toros. En 2010 la derecha política, representada por el Partido Popular, inició los trámites para declarar a las fiestas de toros "Bien de Interés Cultural", en las comunidades autónomas que gobernaba. La defensa pidió respeto para "la fiesta nacional" y las tradiciones

${ }^{13}$ Prou significa "Basta” en catalán. Es la plataforma que se creó ex profeso para lanzar la Iniciativa Legislativa Popular que demandaba la abolición de las corridas de toros. 
españolas, así como libertad para los españoles que quisieran disfrutar de ella. El gobierno español, en ese entonces en manos del Partido Socialista Obrero Español, se declaró partidario de la libre elección, aunque, al final, los diputados socialistas de Cataluña votaron mayoritariamente a favor de mantener la fiesta. En junio de 2010, el Parlament aprobó la prohibición de las corridas de toros. Sin embargo, no todo era lo que parecía: el impedimento sólo aplicaba para el caso de la tauromaquia, para esas celebraciones de enorme influencia andaluza que se había convertido en la fiesta y el espectáculo nacional. No afectaba a las corridas populares.

La discusión política fue muy acalorada y, muy pronto, dejó de lado las preocupaciones animalistas que la habían originado y se convirtió en un debate acerca de una probable "crisis nacionalista española" o de un posible paso a favor de la independencia de Cataluña. Entre los políticos no estaba en juego el sufrimiento animal, sino la posibilidad de alimentar o bloquear un discurso soberanista que desafiara al Tribunal Constitucional. Se abría la posibilidad de distanciarse y diferenciarse del resto de los peninsulares; de subrayar la existencia de una historia particular; de confrontar dos mitideologías identitarias, dos maneras de sentirse autóctono. ${ }^{14}$ Lo que sí estaba en juego, tanto para los políticos catalanes como para los españoles, era aprovechar la ocasión para ostentar y enarbolar aquellos discursos que hablan de su carácter único e incomparable de sus pequeñas naciones; para los más inclinados hacia la derecha fue la oportunidad para anunciar una crisis y despertar viejos espíritus cruzados e invitarlos a luchar a favor de la españolidad.

En fin, en septiembre, dos meses después de la prohibición de la tauromaquia en Cataluña, se aprobó la iniciativa de ley propuesta por del partido nacionalista Convergencia i Unió para el "blindaje" de los correbous, festejos taurinos populares sin muerte. Para la sesión en la que tuvo lugar la votación, los alcaldes y regidores de la Tierras del Ebro acudieron luciendo camisetas con la leyenda: "Soy catalán. Me gustan los toros". Así, los mismos detractores de la tauromaquia, que la rechazaron apelando al maltrato animal, aseguraron que la ley de los correbous estaba llena de elementos identitarios en defensa de la tradición catalana y que no podía compararse con las otras corridas de toros, que ellos no hacían daño al animal. Los tipos de corridas contempladas por la nueva

${ }^{14}$ Empleo el término de "mitideología" propuesto por Marcel Detienne, quien la describe como el armazón de las historias nacionales e identitarias que describen lo que es esencial en la nación y permite el acceso a la autoctonía. Son historias nacionales que definen todo lo que es único e incomparable (2007 [2005]). 
ley, bajo la denominación de correbous, son seis: 1. los bous a la plaça o toros de plaza, que se torean en un recinto cerrado o en un espacio público previamente delimitado con vallas; 2 . los bous al carrer o encierros en los que se corre con los toros por las calles; 3 . los bous capllaçat o toros enmaromados, que se corren por las calles con soga; 4 . los bous embolat o toros embolados, a los que se les colocan dos bolas de fuego sobre los cuernos; 5 . en el toro cerril, se suelta un animal, que nunca ha sido toreado, en una plaza o por las calles; 6. la exhibición de habilidades o de recortadores, donde el torero burla las envestidas sin capa, con saltos o simples movimientos de cintura. ${ }^{15}$

Lo cierto es que estas celebraciones que se han blindado, como elementos identitarios catalanes, forman un conjunto de variantes taurinas que se practican en todo el territorio español e, incluso, en muchos lugares de Iberoamérica. Son esas prácticas que los eruditos de la tauromaquia artística dejaron atrás, como formas primitivas de toreo, carentes de belleza y plástica. Estas fiestas son "las otras" frente a la tauromaquia moderna, las que inevitablemente figuran como premodernas, pertenecientes a un pasado arcaico y presuntamente estable. En ninguna de estas la muerte del animal forma parte de la celebración. Ahí, desde mi punto de vista, radica la paradoja más importante en los estudios de las fiestas de toros. Por un lado, la tauromaquia, práctica que sería considerada la más evolucionada y civilizada de su género, conservaría la muerte del animal, el rasgo más primitivo que permitiría a los especialistas formular una continuidad entre las sociedades totémicas y las corridas artísticas modernas. Sería el vestigio de un viejo ritual dedicado a las deidades de los primeros pobladores de la Península Ibérica o, quizás, de Europa. Por otro lado, las fiestas de toros populares, calificadas como "salvajes" y "arcaicas", se habrían dado a la labor de ocultar la muerte del bovino, a pesar de que el sacrificio -presuponen muchos especialistas- fue el motivo central de estos rituales.

Es por demás evidente que, tanto las celebraciones artísticas como las populares, son igualmente modernas y han sido objeto de constantes transformaciones. Quizás una de las diferencias más importantes entre estas consiste en que unas son las vencedoras y otras son las vencidas. Lamentablemente, no es posible imaginar que las cosas pudieran haber sido distintas si se hubiera impuesto el toreo navarroaragonés sobre el andaluz. Sin embargo, en la batalla contra sus

15 Boletín Oficial del Estado, Legislación consolidada, Ley 34/2010, de 1 de octubre, de regulación de las fiestas tradicionales con toros. Disponible en: https://www.boe.es/buscar/pdf/2010/BOE-A-2010-16138-consolidado.pdf [consultado el 25 de noviembre de 2020]. 
acérrimos opositores todos pueden ser vencidos, dada su notable fragmentación. Cabe mencionar que, en septiembre de 2019, en el municipio de Vidreres (Girona, Cataluña), un toro saltó la barrera durante la celebración de un correbus e hirió a 19 personas. La situación se complicó y la policía tuvo que abatir al animal a tiros. Accidentes de este tipo también han tenido lugar en afamados recintos de la tauromaquia, pero el de Vidreres sirvió de motivo para que, en enero de 2020, se conformara la Plataforma PROU Correbous, con el objetivo de reclamar la abolición de las fiestas populares de Cataluña. Por ahora, en tiempos de pandemia, todo está en suspenso.

\section{OTROS FESTEJOS TAURINOS}

Con los primeros rayos del sol un anciano señala con un par de plumas de águila hacia el oriente. En su lengua amerindia habla con sus ancestros y les comunica que se disponen a cumplir con sus designios, que están a punto de proporcionarles su alimento. A un lado del hombre está tumbado un torete que ha sido atado previamente por las patas; a su alrededor, se han reunido todas las personas que conforman el grupo ritual y portan la parafernalia de los dioses; uno de ello es el responsable de asestar la puñalada que degollará al bovino. Tras la indicación del anciano, la sangre brota a borbollones y es captada en una cubeta. Los participantes se apresuran a ungir con el líquido bermellón toda la parafernalia ritual y las ofrendas que más tarde depositarán en los lugares de culto, donde residen los ancestros deificados. Esta es una escena que se reproduce con mucha frecuencia entre los wixaritari, sociedad indígena que habita en el occidente de México. En esta podemos reconocer, inequívocamente, un auténtico acto sacrificial, dedicado a sus deidades que son pensadas como sus ancestros apicales. De manera independiente a estos holocaustos, suelen realizar otros festejos taurinos en los que se impone el coleadero, ejercicio de acoso a caballo y derribo a mano. ${ }^{16}$ Actualmente, para muchos indígenas americanos su vida tradicional es impensable sin el ganado mayor, sin los sacrificios rituales o los divertimentos taurinos.

En el continente americano no existían los bovinos, ni los equinos, antes del arribo de los conquistadores en el siglo XVI. Estos se reprodujeron con notable rapidez gracias la fertilidad de los campos. Al parecer, hacia 1526, ya se corrían toros en la Nueva España. La crónica de Torquemada (1975 [1615], II, p. 347)

${ }^{16}$ Una descripción detallada de estos coleaderos, pocas veces documentados por lo investigadores, la ha realizado Saumade (2010). 
menciona que en el día de San Juan -de dicho año-, Hernán Cortés recibió la noticia del arribo de Luis Ponce de León mientras presenciaba una corrida. Estas se hicieron cada vez más frecuentes, se llevaron a cabo con motivo de los santos y los eventos importantes de la monarquía (jura del rey, partos de la reina, bodas, etcétera). El ayuntamiento y los religiosos también organizaban fiestas populares de toros, que no eran exclusivas de la élite española. Por ejemplo, Al día siguiente de la entrada del virrey Álvaro Manrique y Zúñiga, en el año de 1585, el arzobispo Pedro de Moya ordenó que se corrieran novillos con bolas de alquitrán en sus cuernos y cohetes. Se encerraron doce animales bravos, a los cuales les pusieron unos cuernos postizos formados con velas e hilo de hierro embetunado con pez, estopa, resina y alquitrán, para encenderlos con fuego. De la misma manera se corrieron toros en la recepción del virrey fray García Guerra y a finales de 1678 (Rangel, 1980 [1924]). Como bien señala Nicolás Rangel, es muy probable que de estas corridas surgieran los festejos en los que se fabrica un toro a partir de una estructura de varas, al cual se le colocan fuegos artificiales en los cuernos, para que baile y juegue a embestir a los participantes. ${ }^{17}$ También había toros de balde, ensogados y becerradas, que son variaciones de las corridas populares. El pueblo disfrutaba de participar en estos encierros, corriendo y burlando a los bovinos.

Todo parece indicar que, desde el siglo XVI, los indígenas participaron activamente en las fiestas taurinas. Hubo discusiones para intentar censurarlas, ya que se dice que muchos de ellos morían entre los cuernos; a ellos se les encomendó que ejecutaran la música durante estos eventos a cambio de una arroba de vino; en las corridas introdujeron el juego del volador y hacían representaciones de danzas de mitote. Los festejos adquirieron formas particulares, frecuentemente, incluían peleas de gallos y carreras de liebre y galgos (Rangel 1980 [1924]). En la Universidad de México, las ceremonias de graduación las celebraban con el tradicional "toro de once", corrida en la que participaba gente de todas las clases sociales.

Según la información proporcionada por Zelaa e Hidalgo (1803, pp. 166-167), acerca de unas fiestas celebradas en Querétaro, en el año de 1680 ya había cuadrillas de toreros de a pie. Entre los lidiadores de la época había algunos españoles, cuyo número se incrementó con el tiempo. Para la segunda mitad del siglo XVIII figuraban como jefes de cuadrilla nombres como Tomás Benegas ("el

17 Un excelente ejemplo contemporáneo de este tipo de celebraciones se puede encontrar en Viento arremolinado. El toro encalado y la flauta de mirlitón de Lizette Alegre (2012). 
Gachupín Toreador"), Pedro Montero -ambos sevillanos- y Juan Sebastián ("el Jerezano"). Según Cossío (1967: 131), estos pudieron ser los introductores en México del nuevo modo de correr y matar toros, tras las innovaciones de Francisco Romero en España. Asimismo, aparecen los primeros intentos de reglamentar la fiesta, en los que se prohibía que el público entrara a la arena durante la lidia, que los espectadores picaran a los animales desde las barreras o lumbreras, y que se vendieran bebidas o alimentos en la plaza (Rangel, 1980 [1924]: 146).

Hacia el siglo XVIII las fiestas de toros eran eventos un tanto sui géneris. Magníficas descripciones al respecto podemos encontrar en Rusticatio mexicana de Rafael Landívar (1965 [1782]). Este poeta jesuita nos habla de corridas divididas en tres tercios y que concluyen con la muerte del animal, lo que permite imaginar que la reglamentación de la tauromaquia fue muy pronto incorporada. También nos habla del jaripeo, una práctica de origen local y que se alternaba con el nuevo toreo para ofrecer variedad. Landívar relata, con sus versos en latín, la manera en que los jóvenes montaban a los toros, los cuales luchaban por lanzar al jinete de su lomo. Luego, una vez que el animal se había agotado, el mismo jinete sobre el bovino blandía una larga pica y mandaba a los toreros de a pie a sacar otro astado, al cual castigaba con la lanza. Entonces, el recién llegado entrecruzaba sus cuernos contra los del toro que llevaba al jinete a cuestas, mientras este dirimía la contienda con la pica, hasta que ambos se fatigaban y se apaciguaban. Este no parece haber sido un ejercicio común, pero sirve para ilustrar las combinaciones que podían surgir. Por su parte, las sociedades nativas se apropiaron a su manera de los ganados y, en estrecho contacto con la alteridad, echaron a volar su creatividad para el empleo de los animales en rituales y entretenimientos.

A lo largo del siglo XIX, comenzó a generarse un conjunto de reglas para lidiar con los bovinos, derribarlos con la mano y lazarlos. Una de las primeras publicaciones al respecto es la de Luis G. Inclán titulada Reglas con que un colegial puede colear y lazar (1969 [1860]); del mismo autor también tenemos Ley de gallos (1969 [1872]), que trata busca regular un evento muy ligado al taurino en México. Se trata de un proceso de estandarización que daría como resultado el espectáculo de la charrería, el cual se definiría más tarde como el "deporte nacional". Todavía a lo largo del siglo XIX, las corridas de la tauromaquia se alternaban con toros encohetados y embolados, jaripeos y coleaderos, entre otras suertes que hoy se han dejado de practicar. Como detalle curioso conviene mencionar que Lencho, el protagonista de la novela Astucia, el jefe de los hermanos de la hoja... escrita por Inclán (2003 [1865]), era un charro 
diestro en el toreo y que usaba su jorongo como muleta, ya que en su juventud había leído un libro titulado La filosofía de los toros, que explicaba el arte de torear y había sido escrito -según el relato- por Francisco Montes. A partir de esas lecciones ensayaba con sus amigos.

Empero, paulatinamente las suertes charras se separarían del toreo andaluz y de las celebraciones populares, para fundar una tradición, un deporte nacional, que se depositaría en manos de las élites ganaderas. Lo mismo haría la tauromaquia local con el propósito de asemejarse más al toreo español. Sin embargo, antes del divorcio definitivo, la tauromaquia y la charrería confluyeron en la figura de Ponciano Díaz (1858-1899), quien vestía de charro, portaba grueso bigote, ponía banderillas a caballo, lazaba reses y también mataba a pie, de una manera distinta a la que se hacía en España. ${ }^{18}$ Su estilo particular de torear le convirtió en un ídolo popular, del público que ocupaba las butacas en el tendido de sol. Su postura era la de un defensor del toreo mexicano contra la tauromaquia de origen español. De alguna manera, deseaba fundar un espectáculo nacional autóctono, inspirado en aquel que había tenido tanto éxito al otro lado del Atlántico. A este movimiento se le denominó "poncianista", pero quizás la confrontación entre los dos estilos de toreo pudo haber venido de tiempo atrás.

Armando de María y Campos (1943) considera que la confrontación inició cuando el torero mexicano Bernardo Gaviño, emprendió una campaña de desprestigio contra los toreros españoles "Cuchares" y "Chiclanero", a los que veía como un peligro para su carrera. Corría el año de 1851 y los toreros españoles se encontraron con los reclamos de una supuesta injuria nacional, ya que no usaban sillas de montar ni garrochas de estilo mexicano. Se dice que esto provocó que los visitantes se pusieran nerviosos y su corrida resultara un fiasco. Varias décadas después, en 1887, Luis Mazzantini y su cuadrilla visitaron México, después de una exitosa temporada en Cuba. El hombre había intentado ser cantante de ópera y se identificaba plenamente con la clase alta. Manuel Horta lo describía como "un señor en la plaza y en las tertulias, un hombre severo y fino que prefiere el frac y los guantes, al pantalón de y a la faja estridente" (1943: 108). Sin lugar a dudas, era un héroe para el público del tendido de sombra, pero los del tendido de sol no pensaban lo mismo. Así, el 16 de marzo, mientras lidiaba con el tercer toro, el público arrojó sillas al ruedo y destrozó las instalaciones de la plaza, la gente fue desalojada y los toreros tuvieron que salir escoltados. Afuera de la plaza de San Rafael, la multitud

${ }^{18}$ Mataba a "bajonazo", estocada que se daba en el cuello del toro. 
despidió a los toreros con pedradas, imprecaciones y mueras contra los españoles, al tiempo que vitoreaban a Ponciano Díaz.

En el trasfondo, había un debate acerca de los vicios y virtudes del toreo mexicano y del español, en un país recientemente independizado. Además, había corrido el rumor de un duelo entre Mazzantini y Ponciano Díaz, el cual nunca se llevó a cabo. Tras este primer incidente se sucedieron otros más, en los que se reclamaba que el verdadero toreo era el de México y que Ponciano era su "profeta". Por su parte, los mazzantinistas llamaban despectivamente "el indio" a Ponciano, en contraste con su héroe al que consideraban todo un caballero (véase Vázquez Mantecón 2001). Las confrontaciones provocaron que se prohibieran las corridas de toros en la Ciudad de México, entre 1889 y 1894; pero, con el tiempo, la polémica fue bajando de tono. El charro torero decidió aprender las suertes españolas, lo que le permitió tomar la alternativa en Madrid el mismo año que inició la prohibición. Al volver, había incorporado en su acuadrilla al banderillero español Saturnino Frutos "Ojitos", quien después formaría una escuela de tauromaquia en México. La separación definitiva de tauromaquia y el toreo mexicano se consumó con la fundación del Círculo Taurino en 1901, cuyo propósito era regularizar y popularizar las reglas españolas del torero.

Antes de que esto sucediera, los charros habían comenzado a buscar un nuevo espacio para sus ejercicios taurino ecuestres y convertirlos en un símbolo nacional. El momento decisivo para la charrería llegó con las celebraciones del primer centenario de la consumación de la Independencia de México (1921), con el nacimiento de la Asociación Nacional de Charros, fundada como una Asociación Deportiva Nacionalista. La charrería se definiría como un "ejercicio físico", identificándose con los sports que se habían desarrollado en Inglaterra durante el siglo XIX. ${ }^{19}$ A partir de entonces conformaron más asociaciones, elaboraron reglamentos más precisos para las suertes charras y diseñaron un nuevo tipo de plaza. El reglamento más conocido de la época fue El libro del charro mexicano de Carlos Rincón Gallardo (1939), en el que todavía se habla de rejonear, torear y banderillear a caballo, ejercicios que más tarde serían abandonados. Sobre estos darían prioridad a otros que tienen que ver con habilidades ecuestres y diversas suertes con lazo. Los ejercicios taurinos que persistieron fueron la jineteada de toros, el coleadero y la terna (dos jinetes lazan a un toro para permitir que otro lo monte). Así se fundó el deporte nacional, cuya custodia fue asumida por grupos de la élite mexicana, distanciándose de las

${ }^{19}$ Acerca de los sports véase Elias (1992 [1986]: 185; 1992 [1982]: 157-160). 
tradiciones populares que aún se siguen practicando fuera de los recintos diseñados para la charrería y la tauromaquia.

En el ámbito popular las competencias de monta de toro son muy comunes y estas mismas se encuentran, a su vez, segmentadas. Por supuesto, no es lo mismo el jaripeo de la charrería que el de los pueblos. De hecho, aun cuando, Rincón Gallardo dedicó un apartado para reglamentarlo, actualmente, los festejos populares no lo contemplan. Por un lado, está la monta de toro charra; por otro, el jaripeo ranchero o popular; $y$, en oposición a ambos, está el rodeo norteamericano, que también se practica en México. Cada uno de estos muestran estilos particulares, pero coinciden en que, al igual que la tauromaquia, se ofrecen como espectáculos masivos. Entre estas modalidades suele observarse cierta confrontación; así la charrería es una expresión de la mexicanidad, es el "deporte nacional"; el rodeo se piensa como un emblema nacional de Estados Unidos, "un deporte estadounidense por esencia" -diría Saumade (2014: 5)-;20 y el jaripeo ranchero es la práctica más popular y que guarda una relación de oposición con las otras, presuntamente, más "civilizadas".

La confrontación parece ser una constante entre los diferentes espectáculos taurinos y se extiende hacía otras prácticas populares, que no necesariamente se constituyen como espectáculos, actividades deportivas o manifestaciones artísticas y que, generalmente, renuncian a competir con las prácticas hegemónicas. La confrontación puede estar vinculada a discursos nacionalistas, pero también al menoscabo de la estima y lucimiento de las fiestas taurinas populares. En los discursos de los toreos hegemónicos prima el juicio a la alteridad, el cual mengua o descredita la estética, los procesos rituales, la expresión dramática, los ejercicios deportivos o el desempeño atlético, la actividad lúdica o la manera en que se ofrece al público como un divertimento. Sin embargo, no todo es absoluta oposición. Por ahora, sólo mencionaré brevemente un caso que he seguido con interés en territorio mexicano.

A finales de 2019, un grupo de importantes empresarios, toreros, promotores y ganaderos se unió a representantes de las comunidades indígenas mayas de la península yucateca. Todos ellos se pronunciaron a través de un documento que

${ }^{20}$ Frédéric Saumade explica la exaltación de los valores patrióticos que se llevan a cabo en el rodeo, "que ha sido y sigue siendo el soporte popular de la imagen del cowboy civilizador y patriota" (2015: 5). Cabe agregar que el miso texto explica que el cowboy estadounidense se opone al mexicano o "mestizo" (half blood o mixed race) definiendose en términos de superioridad racial. 
titularon la Declaración de La Ceiba, ${ }^{21}$ en el que se manifestaban dispuestos a defender los "valores de la tauromaquia" ante los recientes intentos por prohibir dichos festejos en la región, conformada por los estados de Campeche, Yucatán y Quintana Roo. Miembros de la Asociación Nacional de Criadores de Toros de Lidia y representantes de la asociación civil Tauromaquia Mexicana, habían visto que podrían salvar a las corridas en la península de Yucatán si se aliaban con las sociedades indígenas, en las cuales se torea con mucha mayor frecuencia que en las plazas de raigambre hispana. Observaron que, en esta zona del sureste mexicano, acostumbran celebrar más de 2,160 festejos taurinos al año (en más de 370 poblaciones), los cuales se llevan a cabo en los términos que dicta la tradición maya. Era evidente que debían sumarse a los esfuerzos de los locales para defender sus fiestas, aun cuando a estas corridas les reconocían peyorativamente como "chonadas", "corridas informales" o "pachangas" que son celebradas en "plazas de palitos"22 (Rivera 2020). Debo mencionar que estas corridas tradicionales yucatecas son el $70 \%$ de los eventos taurinos actuales en la región (Ceballos 2020).

Si bien es muy clara la influencia, las fiestas de toros de la península de Yucatán no corresponden al canon de la tauromaquia. El evento inicia una noche de alborada o "vaquería", el día anterior a la corrida. Se trata de bailes en los que visten las mejores galas locales y concursan para elegir a los mejores bailadores. Durante este tiempo, un grupo de hombres elegirá una ceiba que plantará en el centro del ruedo, donde se realizarán las corridas. Se trata de un árbol sagrado, el axis mundi, que deben transportar con todos los honores, acompañados con música y cohetes. Después de sembrarlo regresan al baile que termina entre tres y cuatro de la madrugada. Las lidias se llevarán a cabo por la tarde, en cada corrida suelen torear entre diez y veinte astados, los cuales han sido toreados en varias ocasiones. Generalmente, el primer toro es de raza cebú y muere en el ruedo, aunque eso dependerá del dinero disponible y el número de personas asistentes. La carne del animal se vende para preparar un caldo que se conoce

\footnotetext{
${ }^{21}$ Así se denominó porque se firmó en la Ganadería La Ceiba que se encuentra en el municipio de Calotmul, Yucatán.

${ }^{22}$ Los cosos son construidos con gruesas y largas varas, que son atadas con bejucos o mecates de henequén. Sobre la estructura tienden tablados que formarán palcos de dos o tres pisos. Los techos son de hojas guano o palma. Las barreras son celosías hechas con varas, enrejados detrás de los cuales la gente contempla también el espectáculo. En su manufactura se emplea entre una semana y quince días (Medina y Rivas 2010; Ceballos 2020). Al concluir las fiestas son destruidas.
} 
como chocolomo. ${ }^{23}$ Con el astado acostumbran hacer algunos pases con el capone y, luego, ordenan que se le coloquen las banderillas; enseguida, ejecutarán la estocada. En estos festejos se ha suprimido la suerte de varas y, como he mencionado, la muerte no es un requisito. Cuando el toro no muere, el juez de plaza ordena el ingreso de los vaqueros, quienes a caballo lo lazan para conducirlo fuera del ruedo. Al parecer, esta suerte es también parte importante del espectáculo. En una corrida puede haber entre diez y cuarenta jinetes compitiendo por atrapar al bovino (Medina y Rivas 2010; Gabriel 2020; Ceballos 2020).

En algunos lugares, estos festejos que se prolongan por días, introducen las llamadas corridas de postín (término que hace referencia a lo "elegante" o "caro"), en las que participan cuadrillas de toreros profesionales de la tauromaquia, siguiendo la normativa española de los tres tercios. A veces son corridas de medio postín, alternando matadores de tradición hispana, rejoneadores, novilleros o forcados con los toreros locales. Generalmente comienzan con tres o cuatro toros que son lidiados por locales; luego, vendrán los de tradición europea con toros de casta; después, el festejo se reanuda con cuadrillas regionales. También puede haber festivales taurinos en los que participan algunos toreros de tradición europea, con traje corto o de charro, lidian a la portuguesa, aunque eventualmente puede ser a muerte. Pero no todo es espectáculo, también hay ocasión para que toda la comunidad salte al ruedo. El momento llega con el baxal toro o baxal wakax, ${ }^{24}$ cuando se sueltan cebús, media casta o vaquillas para que la gente muestre sus habilidades (Ceballos 2020). Las fiestas pueden culminar con las charlotadas o corridas de charlotes, que se prolongan por días. En estas los toreros se visten caracterizando a una mujer "mestiza", a la "negra Tomasa", al diablo y a la muerte. Los cuatro personajes acosan al toro: uno lo sujeta por la cola, otro por los cuernos, mientras los demás montan al lomo del animal (Medina y Rivas 2010). Podemos decir que es un toreo cómico.

Estas fiestas se celebran principalmente en honor de los santos patrones, aunque también se ven en el Carnaval y ferias de diferentes tipos. Atraen a mucha gente por lo que producen ámbitos de comercialización, de enorme interés económico, pese a que este no ha sido tradicionalmente el objetivo principal. Sin embargo, los empresarios de la tauromaquia han visto en estas costumbres la posibilidad de hacer inversiones, particularmente en este momento donde se ha concretado una

\footnotetext{
${ }^{23}$ Caldo caliente de lomo.

${ }^{24}$ La palabra maya “baxal" corresponde a “jugar", "burlar” o "contender".
} 
alianza exitosa. Esa intrusión propone prácticas que rompen con los motivos esenciales de la celebración maya, por ejemplo, la profesionalización de las corridas al estilo de la tauromaquia; la construcción de plazas temporales de bajo costo que remplazan a los cosos vernáculos; el incremento en la venta de cerveza y otras bebidas alcohólicas, por mencionar algunas. A la vez, y en dirección opuesta, la Declaración de la Ceiba apela al Convenio 169 de la OIT para subrayar, en el punto noveno, el "derecho de las comunidades indígenas a determinar y proteger el sistema cultural y de valores bajo el cual quieren vivir, y no a sufrir la asimilación forzada o la destrucción de su cultura”. Queda claro que la alianza con la tradición occidental no es sencilla, que la tauromaquia también ha sido un atractivo negocio y que no es fácil que el hombre deje de ser su propio depredador.

\section{CONCLUSIONES}

La tauromaquia, como muchos otros festejos taurinos, se encuentran entre el rito y el juego; entre el espectáculo y la hazaña atlética. A su vez, podemos confirmar que se persiguen propósitos estéticos, por lo que no es descabellado pensar que en todos ellos hay arte, que buscan de maneras muy diversas explorar el ámbito de lo sensible. Sin embargo, "no todas las artes son lo mismo". Altas murallas se han levantado entre el arte de la "alta cultura" y el arte popular o la artesanía. También es evidente que no todos los festejos taurinos tienen el deseo de autodefinirse como expresiones artísticas. Recordemos, por ejemplo, que la charrería prefiere pensarse a sí misma como un deporte y la muerte del toro entre los wixaritari es claramente un rito sacrificial. Por supuesto, este último, no es un evento en el que se toreé al animal, pero ¿no convendría contemplar la enorme variedad de tradiciones taurinas para contrastarlas y definirlas de manera más acertada? Comparando a la tauromaquia con el ritual wixarika queda claro que la primera se aleja notablemente de la lógica sacrificial, a pesar de que sus panegiristas se han empeñado en demostrar lo contrario. Entonces, ¿por qué han insistido en interpretar a la tauromaquia como un sacrificio?

La respuesta está clara, dado que la muerte del bovino no era un común denominador para los diferentes tipos de toreo, era preciso subrayar el papel de la tauromaquia como el custodio del "santo grial" taurino: la suerte de espada. Se trata del rasgo que la posiciona como el toreo más antiguo, auténtico y original. Paradójicamente, sería también el festejo taurino más evolucionado y refinado, que habría alcanzado la perfección a través de la evolución, sería el único que había conseguido convertirse en arte y habría llegado a la cumbre de la 
civilización. Con estas premisas opuestas, la tauromaquia parece, por un lado, acercarse a las fiestas populares al reivindicar su antigüedad; pero, por otro lado, se opone a ellas al considerarlas "bárbaras" o "salvajes". Su retórica histórica, se debate entre reivindicar la continuidad de un fenómeno social o la transformación que abona a favor de su refinamiento. Aquí, la oposición entre continuidad y ruptura no es un problema trascendental para las ciencias sociales, sino un discurso ambiguo que se adscribe a una mitideología nacional (véase Detienne 2007 [2005]). La mitideología o ideología nacional busca dar cierta unidad entre la diversidad que constituye al estado-nación; pretende hacer pensar a sus habitantes que conforman una "raza" de autóctonos, que han sido los mismos desde los orígenes, pero que al mismo tiempo son civilizados con respecto a otros; los muestra como portadores de una historia, que es única e incomparable, más nacional y menos comparativa, que piensa a la nación por la nación; les proporciona relatos de raigambre exclusiva, les dice cómo ser autóctonos.

Empero, la tauromaquia no es la única que ha incursionado en las mitologías nacionales, también la charrería se ha entregado plenamente a esa labor y lo suyo también se ha hecho con los correbous y el rodeo estadounidense. Todos estos, al evadir la comparación con los otros, consiguen mostrarse como únicos en su especie, como elementos fundamentales y fundacionales de la nación, al tiempo que se oponen a la alteridad y reivindican una forma de autoctonía. Estas identidades constitutivas nacionales generan la fragmentación de un complejo ritual, confrontan tradiciones histórica y socialmente hermanadas. Así, desde el punto de vista académico, se impone la necesidad de analizar este complejo en términos comparativos, desnacionalizando las historias nacionales, reivindicando la humanidad de lo que ha sido deshumanizado en la definición de la alteridad.

En un documental mexicano dedicado a Francis Wolff, el filósofo taurino expresó con tristeza y pesimismo que la tauromaquia está inevitablemente condenada a morir..$^{25}$ Lo cierto es que la fragmentación del complejo ritual y la elaboración de historias que se consideran únicas no abonan a que esto sea de otra manera. Por su parte, a los panegiristas y aficionados a los festejos de taurinos les convendría reflexionar acerca de sus impulsos fratricidas. Ese combate entre hermanos, esa actitud elitista que relega a muchos al olvido, solo despeja el camino sin retorno que conduce a su desaparición. La alternativa podría consistir en dejar de contemplar a las fiestas taurinas como emblemas

\footnotetext{
${ }^{25}$ Jesús Muñoz y Aarón Fernández (directores), Un filósofo en la arena, 2018.
} 
exclusivistas y subrayar que se trata de un importante rasgo cultural iberoamericano, rico en su diversidad.

\section{BIBLIOGRAFÍA}

ALEGRE, L. (2012): Viento arremolinado. El toro encalado y la flauta de mirlitón, Xalapa, Consejo Nacional para la Cultura y las Artes / Instituto Veracruzano de la Cultura.

ÁlVAREZ DE MIRANDA, Á. (1998 [1962]): Ritos y juegos del toro, Madrid, Biblioteca Nueva.

ANÓNIMO (circa s. XVIII): Cartilla en que se notan algunas reglas de torear a pie en verso y prosa, manuscrito.

BENNASSAR, B. (2000): Historia de la tauromaquia. Una sociedad del espectáculo, Valencia, Real Maestranza de Caballería de Ronda.

CARMENA Y MILLÁN, L. (1888): Tauromaquia. Apuntes bibliográficos, Madrid, Imprenta de José M. Ducazcal.

CEBALLOS, R. (2020): "De la diversidad del toreo peninsular", La fiesta no manifiesta. La península de Yucatán y su tauromaquia, Ciudad de México, Tauromaquia Mexicana, pp. 43-51.

COSsíO, J. M. de (1965 [1943-1961]): Los toros. Tratado técnico e histórico, tomo II, Madrid, Espasa- Calpe.

COSSÍO, J. M. de (1967 [1943-1961]): Los toros. Tratado técnico e histórico, tomo IV, Madrid, Espasa- Calpe.

DELGADO, J. (Pepe Hillo) (1946 [1796]): La tauromaquia o arte de torear, Madrid, Viuda de Galo Sáez.

DÉSVEAUX, E. y SAUMADE F. (1998). "Relativizar el sacrificio o el cuadrante taurómaco", Demófilo. Revista de cultura tradicional de Andalucía, 25, Sevilla, Fundación Machado, pp. 236-243.

DETIENNE, M. (2007 [2005]): Los griegos y nosotros. Antropología comparada de la Grecia antigua, Madrid, Akal.

ELIAS, N. (1992 [1982]): "La génesis del deporte como problema sociológico", Deporte y ocio en el proceso de la civilización, editado por Norbert Elias y Eric Dunning, Madrid, Fondo de Cultura Económica, pp. 157-184. 
ELIAS, N. (1992 [1986]). "Introducción", Deporte y ocio en el proceso de la civilización, editado por Norbert Elias y Eric Dunning, Madrid, Fondo de Cultura Económica, pp. 31-81.

FERNÁNDEZ DE MORATÍN, N. (1850 [1777]): “Carta histórica sobre el origen y progreso de la fiesta de toros en España", en Obras de D. Nicolás y D. Leandro Fernández de Moratín (Biblioteca de autores españoles, 2), Madrid, M. Rivadeneyra, pp. 141-144.

GABRIEL, M. (2020): "La razón del festejo. Las promesas en los festejos taurinos en la Península de Yucatán”, La fiesta no manifiesta. La península de Yucatán y su tauromaquia, Ciudad de México, Tauromaquia Mexicana, pp. 31-41.

GALVAM D'ANDRADE, A. (1678): Arte da cavallaria de gineta, e estardiota, bom primor de ferrar et alveiteria L'Alucitaria, Lisboa, Joam da Costa.

GARCÍA-BAQUERO, A., ROMERO DE SOLÍS, P., VÁZQUEZ PARLADÉ, I. (1980): Sevilla y la fiesta de toros, Sevilla, Ayuntamiento de Sevilla (Biblioteca de temas sevillanos, 5).

GARCÍA-BAQUERO, A. (1990): "El marcelo sevillano y los orígenes de la tauromaquia moderna”, Taurología, 2, Madrid, Editorial Brindis, pp. 38-44.

GARCÍA BARAGAÑA, E. (1750): Noche phantastica, ideático divertimento, que demuestra el methodo de torear a pie, Madrid, Imprenta de Antonio Pérez de Soto.

GUILLAUME-ALONSO, A. (1994): La tauromaquia y su génesis (siglos XVI y XVII), Bilbao, Ediciones Laga.

GUILLAUME-ALONSO, A. (2010): "Las fiestas de toros en el Madrid crepuscular de Carlos II. Crónica de una evolución imparable”, Revista de Estudios Taurinos, 28, Sevilla, pp. 81-109.

GUILLAUME-ALONSO, A. (2016) "El caballero, el toro y el príncipe", en Tauromaquia. Historia, arte, literatura y medios de comunicación en Europa y América, editado por F. H. Álvarez y P. Romero de Solís, Sevilla, Fundación Real Maestranza de Caballería de Sevilla / Universidad de Sevilla / Fundación de Estudios Taurinos.

HORTA, M. (1943): Ponciano Díaz (silueta de un torero de ayer), México. Imprenta Aldina.

HURTADO, P. (1989 [1902]): Supersticiones extremeñas, Cáceres, A. Artero Hurtado. 
INCLÁN, L. G. (1969 [1860]): "Reglas con que un colegial puede colear y lazar", en Hugo Aranda Pamplona, Luis Inclán "El Desconocido", México, Manuel Quesada Brandi, pp. 135-178.

INCLÁN, L. G. (1969 [1872]): “Ley de gallos”, en Hugo Aranda Pamplona, Luis Inclán “El Desconocido”, México, Manuel Quesada Brandi, pp. 193-212.

INCLÁN, L. G. (2003 [1865]): Astucia, el jefe de los hermanos de la hoja, o los charros contrabandistas de la Rama. Novela histórica de costumbres mexicanas con episodios originales, México, Editorial Porrúa (Colección sepan cuantos..., 63).

LANDÍVAR, R. (1965 [1782]): Rusticatio mexicana. Por los campos de México, México, Editorial Jus.

MARÍA Y CAMPOS, A. de (1943): Ponciano, el torero con bigotes, México, Ediciones Xochitl (Vidas mexicanas, 7).

MEDINA HERNÁNDEZ, A. y RIVAS CETINA, F. J. (2010): "La corrida de toros en los pueblos mayas orientales. Una aproximación etnográfica", Estudios de Cultura Maya, XXXV, pp. 2010.

MEDINA MIRANDA, H. (2014): "Fabulaciones taurológicas y sacrificios rituales: disertaciones histórico antropológicas en torno a las fiestas de toros", $A I B R$. Revista de Antropología Iberoamericana, volumen 9, número 1, 2014, pp. 75-98.

MILLÁN, P. (1890): Los toros de Madrid. Estudio histórico, Madrid, Imprenta y litografía de Julián Palacios.

MONTES, F. (Paquiro) (1983 [1836]): Tauromaquia completa o sea arte de torear en plaza, Madrid, Turner.

NAVAS, Conde de las (Juan Gualberto López Valdemoro de Quesada) (1899): El espectáculo más nacional, Madrid, Sucesores de Rivadeneyra.

PÉREZ DE NAVARRETE, F. (1626): Arte de enfrenar, Madrid, Iuan Gonzalez.

RANGEL, N. (1980 [1924]): Historia del toreo en México. Época colonial [15291821], México, Editorial Cosmos.

RAMÍREZ DE HARO, D. (1961 [1551]): El tratado de la brida y jineta y de las caballerías que en entrambas sillas se hacen y enseñan a los caballos y de las formas de torear a pie y a caballo, Madrid, Unión de Bibliófilos Taurinos (Colección Carmena, 4).

RIVERA RODRÍGUEZ, A. (2020): "Antecedentes históricos. De las cosas de antes, las de siempre...”, La fiesta no manifiesta. La península de Yucatán y su tauromaquia, Ciudad de México, Tauromaquia Mexicana, pp. 19-29. 
REAL ACADEMIA ESPAÑOLA (1739): Diccionario de autoridades, tomo VI, Madrid, Imprenta de Francisco del Hierro.

REAL ACADEMIA ESPAÑOLA (1817): Diccionario de la lengua castellana por la Real Academia Española, quinta edición, Madrid, Imprenta Real.

REAL ACADEMIA ESPAÑOLA (1884): Diccionario de la lengua castellana por la Real Academia Española, duodécima edición, Madrid, Imprenta de D. Gregorio Hernando.

RODRÍGUEZ RUBÍ, T. (1843): "El torero", Los españoles pintados por sí mismos, tomo I. Madrid, I. Boix Editor, pp. 1-8.

SAN JUAN DE PIEDRAS ALBAS, Marqués de (Bernardino de Melgar y Abreu) (1927): Fiestas de toros: bosquejo histórico, Madrid, Tipográfica A. Marzo.

SAUMADE, F. (1996): "Los ritos de la Tauromaquia entre la cultura erudita y la cultura popular", Revista de Estudios Taurinos, 4, Sevilla, Fundación de Estudios Taurinos, pp. 125-162.

SAUMADE, F. (2006): Las tauromaquias europeas. La forma y la historia, un enfoque antropológico, Sevilla, Fundación Real Maestranza de Caballería de Sevilla / Universidad de Sevilla / Universidad de Granada (Colección Tauromaquias, 8).

SAUMADE, F. (2010): “¿Pueden los indios modernos convertir al hombre blanco? Fiesta patronal y rodeo entre los huicholes del occidente mexicano", Cuicuilco, volumen 17, número 48, 2010, pp. 229-256.

SAUMADE, F. (2014): “Ganadería, tauromaquia y subversión ritual: el retorno del mexicano y del indígena en el rodeo americano", Comprender los rituales ganaderos en los Andes y más allá. Etnografías de lidias herranzas y arrierías, editado por Juan Javier Rivera Andía, Bonn, Förderverein Bonner Amerikanistiche Studien, pp. 365-400.

TORO, Buiza, L. (2002 [1947]): Sevilla en la historia del toreo, Sevilla, Fundación Real Maestranza de Caballería de Sevilla / Universidad de Sevilla / Fundación de Estudios Taurinos.

TORQUEMADA, J. de (1975 [1615]): Monarquía indiana, volumen II, México, Instituto de Investigaciones Históricas-Universidad Nacional Autónoma de México (Serie de historiadores y cronistas de indias, 5).

VÁZQUEZ MANTECÓN, M. del C. (2001): "Charros contra gentleman. Un episodio de identidad en la historia de la tauromaquia mexicana moderna”, Modernidad, tradición y alteridad, editado por Claudia Agostoni y Elisa Speckman, México, Instituto de Investigaciones Históricas de la Universidad Nacional Autónoma de México, pp. 161-193. 
WOLFF, F. (2010 [2007]): Filosofía de las corridas de toros, Barcelona, Ediciones Bellaterra.

ZELAA E HIDALGO, J. M. (1803): Glorias de Querétaro, en la fundación y admirables progresos de lo muy I. y Ven. Congregación Eclesiástica de Presbíteros Seculares de María Santísima de Guadalupe de México, México, Oficina de D. Mariano Joseph de Zuñiga y Ontiveros.

Recibido: 17 de diciembre de 2020

Aceptado: 19 de enero de 2021

Héctor Medina Miranda es profesor investigador titular del CIESAS Occidente y miembro del Sistema Nacional de Investigadores en México. De 2010 a 2017 fue Profesor Investigador de tiempo completo de la UASLP. Es doctor en antropología por la Universidad de Salamanca; Maestro en la misma disciplina con especialidad en etnología por la UNAM; licenciado en antropología social por la ENAH. Ha realizado investigaciones acerca de los estereotipos ganaderos en España y en México, así como de los rituales taurinos y las tradiciones ganaderas en ambos lados del Atlántico. Además, ha estudiado la organización social, los rituales y la mitología wixarika, en perspectiva histórica y antropológica. Entre sus publicaciones más recientes se encuentran: Vaqueros Míticos. Antropología comparada de los charros en España y en México (Gedisa, 2020) y Los wixaritari. El espacio compartido y la comunidad (CIESAS, 2020). hector.medina@ciesas.edu.mx 